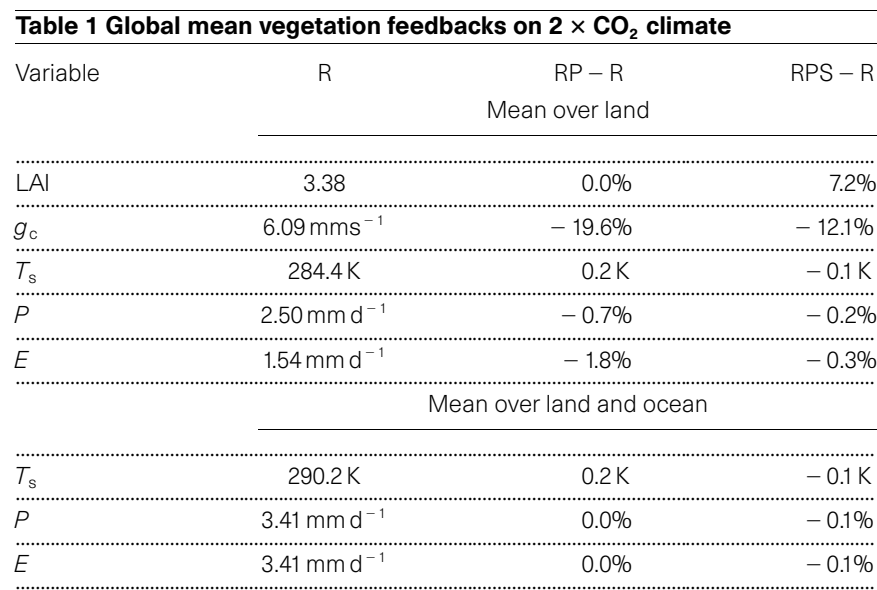

Mean values and perturbations to leaf area index (LAl), canopy conductance $\left(g_{\mathrm{c}}\right)$, screenlevel temperature $\left(T_{\mathrm{s}}\right)$, total precipitation $(P)$ and total surface moisture flux $(E)$. Column 2 shows absolute values for simulation $\mathrm{R}$ (radiation only), column 3 shows the changes due to the physiological response only (RP $-\mathrm{R})$, and column 4 gives the total vegetation feedback (RPS $-\mathrm{R})$. Changes are given as percentages of the value in simulation $\mathrm{R}$, except for temperature changes which are given in $\mathrm{K}$.

increased masking of snow. The feedback through evaporation was significantly modified by structural changes, especially in the middle- and high-latitude regions (compare Fig. $3 \mathrm{c}$ and g). However, transpiration from the tropical rainforests, which experienced negligible changes in LAI, was still significantly reduced compared to simulation $\mathrm{R}$.

It is important to recognize that changes in vegetation structure may lag the physiological response to increased $\mathrm{CO}_{2}$ by several years or even decades. Therefore, the actual effect of vegetation feedback on climate at the time of $\mathrm{CO}_{2}$ doubling is likely to lie somewhere between the results of simulations RP and RPS. A full assessment of this will require a model of vegetation dynamics fully integrated within a GCM. Nevertheless, our results show that changes in land surface properties due to vegetation can provide climatic feedback mechanisms that are both positive and negative in relation to climate change due to radiative forcing alone; furthermore, they demonstrate that the sign of the feedback depends partly on whether local vegetation growth is enhanced or suppressed by increased $\mathrm{CO}_{2}$ concentration and the associated climate change, and partly on the nature of the locally dominant surface-atmosphere interaction. Both physiological and structural characteristics of the vegetation have been shown to be important, with changes in one property often counteracting changes in another. In the global mean, the competing effects of increased water use efficiency and increased LAI cause a small surface evaporation change relative to the climate change simulation with fixed vegetation properties. We conclude that a short-term enhancement of regional climate warming by vegetation physiology may eventually be mitigated by a longer term modification of surface characteristics due to vegetation morphology. As this work does not account for the timescales involved in the full suite of vegetation feedbacks, the next stage should be to include dynamical changes in both vegetation physiology and structure in GCM predictions of future climate change.

Received 28 October 1996; accepted 28 April 1997

1. Houghton, J. T. et al. (eds) Climate Change 1995 (Cambridge Univ. Press, 1995).

2. Sellers, P. J. et al. Comparison of radiative and physiological effects of doubled atmospheric $\mathrm{CO}_{2}$ on climate. Science 271, 1402-1406 (1996).

3. Lean, J. \& Rowntree, P. R. A GCM simulation of the impact of Amazonian deforestation on climate using an improved canopy representation. Q. J. R. Meteorol. Soc. 119, 509-530 (1993).

4. Bonan, G. B., Pollard, D. \& Thompson, S. L. Effects of boreal forest vegetation on global climate. Nature 359, 716-718 (1992).

5. Foley, J. A., Kutzbach, J. E., Coe, M. T. \& Levis, S. Feedbacks between climate and boreal forests during the Holocene epoch. Nature 371, 52-54 (1994).

6. Gallimore, R. G. \& Kutzbach, J. E. Role of orbitally induced changes in tundra area in the onset of glaciation. Nature 381, 503-505 (1996).

7. Woodward, F., Smith, T. M. \& Emanuel, W. R. A global land primary productivity and phytogeography model. Glob. Biogeochem. Cycles 9, 471-490 (1995).
8. Mitchell, J. F. B., Johns, T. C., Gregory, J. M. \& Tett, S. F. B. Climate response to increasing levels of greenhouse gases and sulphate aerosols. Nature 376, 501-504 (1995).

9. Jones, R. G., Murphy, J. M. \& Noguer, M. Simulation of climate change over Europe using a nested regional-climate model. I: Assessment of control climate, including sensitivity to location of lateral boundaries. Q. J. R. Meteorol. Soc. 121, 1413-1449 (1995).

10. Senior, C. A. \& Mitchell, J. F. B. Carbon dioxide and climate: the impact of cloud parameterization. J. Clim. 6, 393-418 (1993)

11. Chen, T. H. et al. Cabauw experimental results from the project for intercomparison of land-surface schemes (PILPS). J. Clim. (in the press).

12. Rowntree, P. R. \& Bolton, J. A. Simulation of the atmospheric response to soil moisture anomalies over Europe. Q. J. R. Meteorol. Soc. 109, 501-526 (1983).

13. Beljaars, A. C. M., Viterbo, P., Miller, M. J. \& Betts, A. K. The anomolous rainfall over the United States during July 1993: sensitivity to land surface parameterization and soil moisture anomalies. Mon. Weath. Rev. 124, 362-383 (1996).

14. Milly, P. C. D. \& Dunne, K. A. Sensitivity of the global water cycle to the water-holding capacity of land. J. Clim. 7, 506-526 (1994).

15. Rowntree, P. R. in Land Surface Evaporation (eds Schmugge, T. J. \& Andre, J. C.) 5-30 (Springer, New York, 1991).

16. Wilson, M. F. \& Henderson-Sellers, A. A global archive of land cover and soils data for use in general circulation climate models. J. Climatol. 5, 119-143 (1985)

17. Sellers, P. J., Mitz, Y., Sud, Y. C. \& Dalcher, A. A simple biosphere model ( $\mathrm{SiB})$ for use within general circulation models. J. Atmos. Sci. 43, 505-531 (1986).

18. Lowry, W. P. \& Lowry, P. P. Fundamentals of Biometeorology. Interactions of Organisms and the Atmosphere Vol. 1 (Peavine, McMinnville, OR, 1989).

19. Eagleson, P. S. Dynamic Hydrology (McGraw Hill, New York, 1970).

20. Halldin, S., Saugier, B. \& Pontailler, F. Y. Evapotranspiration of a deciduous forest. Simulation using routine meteorological data. J. Hydrol. 75, 323-341 (1984).

21. Shaw, R. H. \& Pereira, A. R. Aerodynamic roughness of a plant canopy. Agricult. Meterol. 26, 51-65 (1982).

Acknowledgements. We thank E. M. Blyth, J. Foley, R. J. Harding, W. J. Ingram, J. E. Lovelock, J. F. B. Mitchell, P. L. Mitchell, P. R. Rowntree, C. A. Senior, W. J. Shuttleworth, S. F. B. Tett and P. J. Valdes for comments, advice and discussion. This work was supported by the NERC TIGER programme and the UK Department of the Environment.

Correspondence and requests for materials should be addressed to R.A.B. (e-mail: rabetts@meto.gov.uk)

\section{Wing upstroke and the evolution of flapping flight}

\section{Samuel O. Poore, A. Sánchez-Haiman \& G. E. Goslow Jr}

Department of Ecology and Evolutionary Biology, Brown University, Providence, Rhode Island 02912, USA

Movements of the wing during upstroke in birds capable of powered flight are more complex than those of downstroke $\mathrm{e}^{1-3}$. The $\mathrm{m}$. supracoracoideus (SC) is a muscle with a highly derived morphology that is generally considered to be the primary elevator of the wing $^{4-6}$. This muscle arises from the ventrally oriented sternum and its tendon of insertion passes craniodorsally through a special bony canal, around a bony process which deflects it laterally, to attach on the dorsal aspect of the humerus above the glenohumeral joint (Fig. 1). We studied the contractile properties of the SC in situ and related them to wing kinematics in the European starling (Sturnus vulgaris). Our findings indicate that the primary role of the SC is to impart a high-velocity rotation about the longitudinal axis of the humerus. This rapid 'twisting' of the humerus, coupled with limited humeral elevation, is responsible for positioning the forearm and hand so that their subsequent extension orients the outstretched wing appropriately for the following downstroke. This reinterpretation of the primary function of the SC provides insight into the selective advantage of its unique musculoskeletal organization in the evolution of powered flapping flight in birds.

A general feature of powered locomotion based on an oscillating wing is an asymmetry in how the wing meets the environment during the downstroke compared with the upstroke parts of the wingbeat cycle ${ }^{7}$. The downstroke in birds, when primary lift and propulsion are achieved, is characterized by an outstretched wing. The more complicated upstroke involves rapid withdrawal of the wing towards the body to reduce its surface area, elevation and subsequent extension in a way that minimally retards lift and thrust gained in the previous downstroke. The distinct musculoskeletal configuration of the $\mathrm{m}$. supracoracoideus (SC) was not present in 
the Jurassic bird Archaeopteryx $x^{8,9}$, nor is there firm evidence for its presence in recently described Late Jurassic or Early Cretaceous species $^{10-15}$. The evolution of this condition is thought to have been important for flapping powered flight in improving the function of wing elevation ${ }^{16,17}$, but the significance of its highly derived organization has not been appreciated.

We measured isometric forces of rotation (torque) about the longitudinal axis of the humerus, the extent of unrestrained humeral elevation and rotation, and the muscle's contractile properties, by direct nerve stimulation of the SC in situ. Stimulation of the SC at joint angles of elevation/depression and protraction/retraction coincident with the downstroke-upstroke transition and midupstroke $^{2}$ imparted a substantial mean isometric torque about the longitudinal axis of the humerus (Fig. 2). A mean isometric value of $4.9 \mathrm{~N}(n=2)$ was recorded at the downstroke-upstroke transition. In the humeral excursion experiments, we measured in situ humeral rotations of up to $70^{\circ}$ and maximum elevations of $50^{\circ}$. In three length-force experiments, we measured a mean ( \pm s.d.) maximal tetanic force of $6.5( \pm 1.2) \mathrm{N}$, approximately 10 times body weight. The length of the SC coincident with the downstroke-upstroke transition corresponds to a position on the ascending limb of the active length-force curve of $3.0 \mathrm{~N}$ (Fig. 3). In lateral view, the right humerus rotates anticlockwise about its longitudinal axis and elevates a total of $50^{\circ}$ during upstroke $\left(-10^{\circ}\right.$ to $\left.40^{\circ}\right)$; these movements correspond to muscle shortening of $3.0 \mathrm{~mm}$ and a coincident decrease in the SC's potential for active force production (Fig. 3). The ascending arm of the active length-force curve occurs over a short distance $(5 \mathrm{~mm})$ and is steep owing to the short fascicle lengths associated with the SC's bipinnate architecture. These data reveal that, although the SC is capable of elevation of the humerus, a far more important role is to provide a high-velocity rotation about its longitudinal axis.

Further support for this conclusion can be drawn from the mechanical organization of the SC, its electrical activity patterns reported during slow and fast flight, and the highly derived morphology of the avian shoulder. The bipinnate structure of the SC, with its relatively short but numerous fascicles characteristic of all birds we examined, is an architecture for production of high

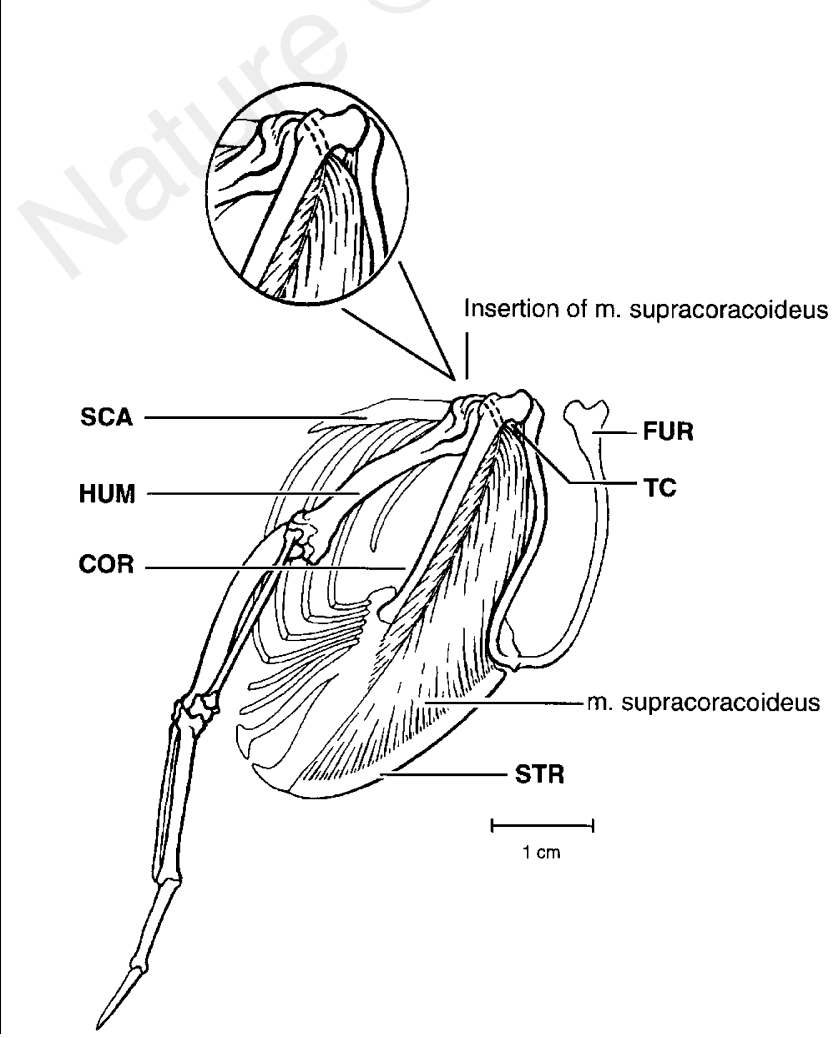

force. The SC's moment arm for humeral rotation about the longitudinal axis is short; we estimate its maximum in the starling to be $2.0 \mathrm{~mm}$. When a large torque (as provided by the SC) is applied across this short moment, the resultant velocity of humeral rotation and its attached distal wing element is magnified.

Aerodynamic models predict that active muscle contractile force is far more important for wing elevation in birds during slow than in fast flapping flight ${ }^{18}$. Passive aerodynamic lift is sufficient at fast flight speeds, particularly in birds with high-aspect ratio wings. In four species of birds with diverse flight styles for which electromyograms of the SC during flight have been reported, however, the muscle remains electrically active over a range of flight speeds ${ }^{2,4,19,20}$. Passive aerodynamic lift may not be implemented at the flight speeds attained in these experimental situations. The SC may act to adjust the planform of the wing's leading edge at all speeds. Electromyographic activity does not necessarily correlate with useful mechanical force ${ }^{21}$ and its presence may simply reflect outflow modulation of a central neural control program ${ }^{22}$. Or, as we believe, the activity of the SC at even high flight speeds is necessary for its most important role, that of humeral rotation.

The avian shoulder joint is structurally derived and functionally complex. The glenoid, best described as a hemisellar (half saddle) joint, is concavoconvex in configuration, faces dorsolaterally, and articulates with a bulbous humeral head. Jenkins ${ }^{23}$ reviewed the evolution of this joint in a comparative study and provided a new interpretation of its functional morphology based on a cineradiographic analysis of the wingbeat cycle. The articulation of the humeral head on the dorsally facing surface of the glenoid (the Labrum cavitatis glenoidalis) at the upstroke-downstroke transition allows full abduction of the wing into the parasagittal plane. Our observations further reveal that this extensive abduction of the wing, characteristic of so many flying birds, is accomplished not by simple elevation of the humerus, but primarily by rotation about its longitudinal axis.

In a classic study of the functional organization of the wing ${ }^{24}$, Sy described humeral axial rotation as a mechanism for the execution of wing upstroke in pigeons and generalized its importance for other relatively small birds with powered flight. To appreciate the

Figure 1 Anterolateral view of the right shoulder in the European starling (Sturnus vulgaris). The $\mathrm{m}$. pectoralis has been removed, as well as all other wing and shoulder musculature to expose the m. supracoracoideus (SC) and its tendon of insertion on the dorsal aspect of the humerus. The fascicles of the SC arise from the dorsal half of the carina, the adjacent body of the sternum, and a small area on the base of the coracoclavicular membrane. The SC's bipinnate architecture limits tendon excursion but maximizes force production. Scale bar, $1.0 \mathrm{~cm}$. Abbreviations: SCA, scapula; HUM, humerus; COR, coracoid; TC, triosseal canal; FUR, furcula, STR, sternum. 
functional significance of this rotation, it is necessary to consider the orientation of the humerus to the body axis. When viewed from above (in dorsal view), the angle formed by the long axis of the humerus and the bird's longitudinal axis when the wing is in the downstroke-upstroke transition position is not $90^{\circ}$ as might be expected: the humerus is retracted back towards the body to form an acute angle with the long axis of the back. At the downstrokeupstroke transition in starlings, for example, this angle is at its maximum of $55-60^{\circ}$ during early upstroke, and decreases to its minimum of $25-30^{\circ}$ (that is, the humerus is retracted). Simple elevation of a retracted humerus orients the wing's ventral surface posterolaterally instead of in the more functional lateral position. Simultaneous rotation and elevation of the humerus in early upstroke is necessary so that subsequent extension of the hand and forearm during late upstroke will orient the fully outstretched wing in the parasagittal plane; that is, the wing's ventral surface will face laterally, the position appropriate for the beginning of the subsequent downstroke. Humeral rotation/retraction as described here is key to the execution of high-amplitude, high-frequency wingbeats in the European starling, a generalized member of the order Passeriformes, and may also be important in other birds, including those with longer wings, as well as for other flying vertebrates. For example, in a study of the shoulder of the Cretaceous pteryodactyloid pterosaur Santanadactylus brasilensis, which has an estimated body mass of $3.9-7.3 \mathrm{~kg}$ and a total wingspan of $4.7 \mathrm{~m}$, humeral rotation was proposed to be the key to wing elevation in this species ${ }^{25}$.

In the seven preserved specimens of the Jurassic bird Archaeopteryx, there is no evidence of a derived SC with a dorsally inserting tendon, as indicated by the lack of a triosseal canal or an

\section{Downstroke-upstroke transition}

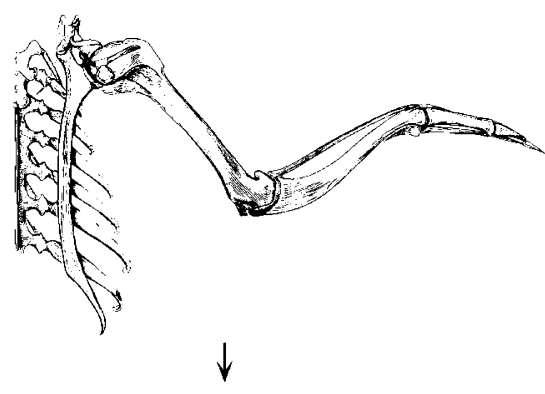

Rotational force $(\mathrm{N})$

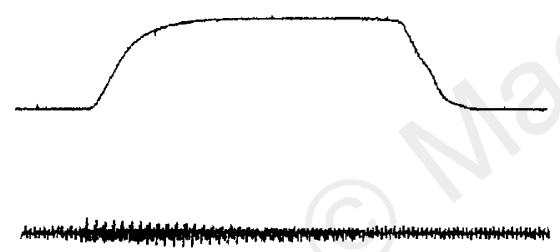

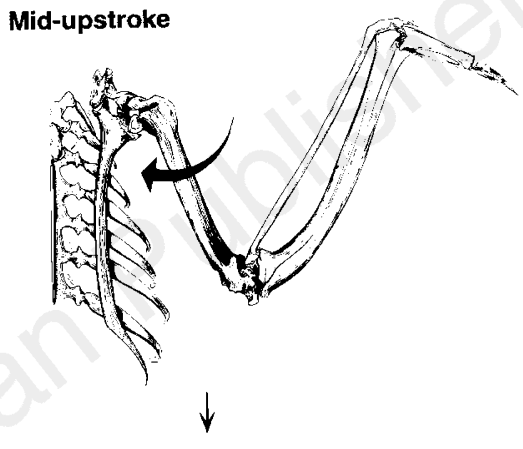

Rotational force $(\mathrm{N})$

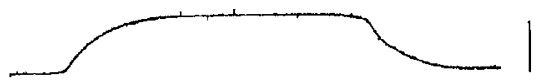

Figure 2 Rotational force of the $\mathrm{m}$. supracoracoideus (SC) measured at the deltopectoral crest. We measured in situ isometric rotational force (torque) produced by the SC in two experiments at two positions of the humerus relevant to the wingbeat cycle; downstroke-upstroke transition (a) and mid-upstroke (b). Force measured at the downstrokeupstroke transition (a) was consistently higher than that at mid-upstroke (b). The moment arm of the SC for rotation is short $(2 \mathrm{~mm})$. The resulting mechanical advantage for rotation of the humerus by the SC is relatively low, but when input forces are high, the arrangement is favourable for the production of high-velocity rotation at the distal wing. Time bar, $100 \mathrm{~ms}$; force bar, $2.5 \mathrm{~N}$.

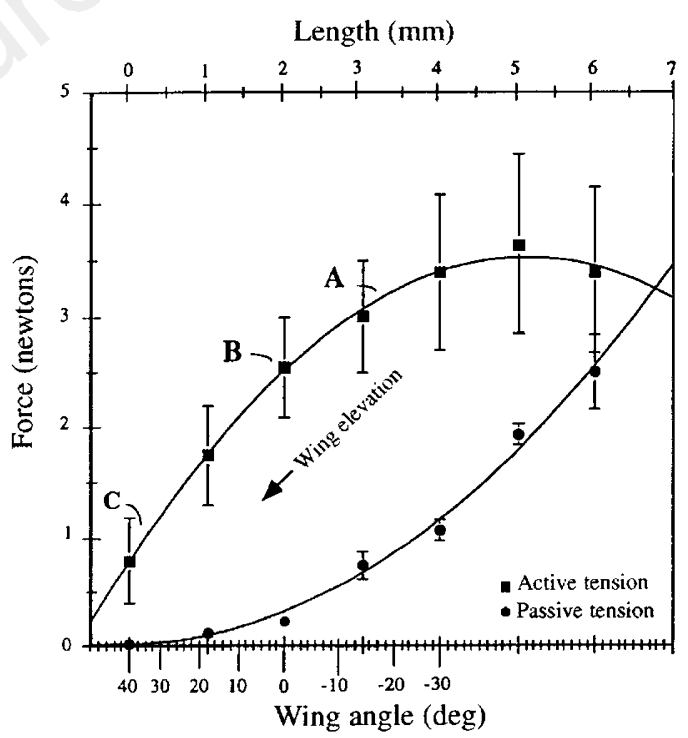

Figure 3 Functional correlates of length-force in European starlings (Sturnus vulgaris). Top, active and passive length-force characteristics of the supracoracoideus muscle derived by direct nerve stimulation from four in situ experiments. Bottom, anterior views of the right shoulder at the downstrokeupstroke transition (A), mid-upstroke (B) and late upstroke (C). The humerus is

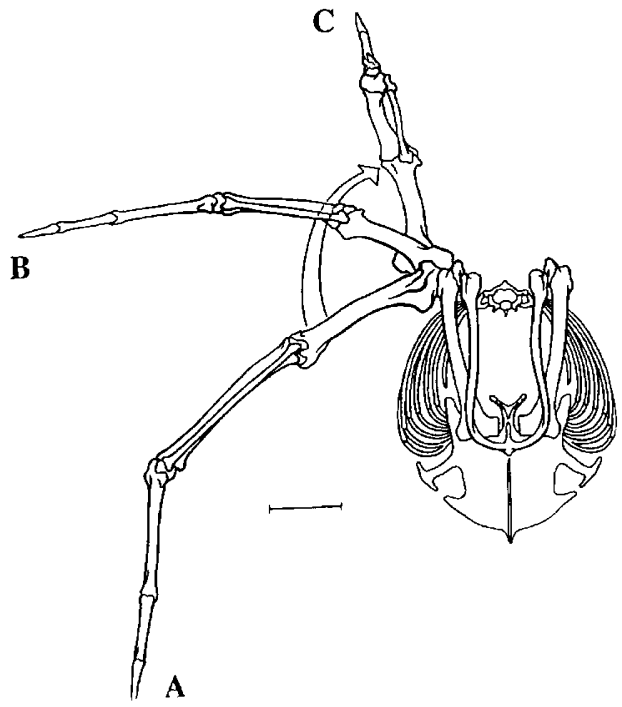

depressed $10^{\circ}$ below the horizontal at the downstroke-upstroke transition, which corresponds to a position on the ascending arm of the active length-force curve (A) where the muscle is capable of producing $85 \%$ of total force. As the wing is elevated/rotated to the mid-upstroke $(B)$ and late-upstroke $(C)$ positions, the capacity for force production by the SC declines. Scale bar, $1.0 \mathrm{~cm}$. 
acrocoracoid $^{8,9,26,27}$. The lack in Archaeopteryx of this organization, and therefore of rapid humeral rotation, may have restricted its ability to execute rapidly the high-amplitude wing movements associated with slow flight, take-off and landing in modern species of similar size. The early fossil record of birds since the Jurassic demonstrates a number of advanced characteristics that signal evolutionary improvements towards powered flight. For example, the glenoid of Archaeopteryx and the glenoid of the younger Lower Cretaceous Sinornis both face laterally ${ }^{8,9,23}$, which presumably limited extensive abduction of the wing into the parasagittal plane in both species. In the recently described series of Enantiornithine and non-Enantiornithine Mesozoic birds (that is, Eoalulavis, Neuquenornis, Cathayornis, Concornis, Ambiortis and Iberomesornis $)^{10,12,15,28-30}$, the presence of an elongated coracoid, furcula and scapular acromion suggests that a derived SC may have been present, although an acrocoracoid or triosseal canal has not been identified de facto.

Our reinterpretation here of the primary action of the SC, that of high-velocity humeral rotation, explains a new aspect of the evolutionary significance of its highly derived morphology in birds. The selective advantage of high-velocity rotation of the humerus to position the wing appropriately for downstroke was undoubtedly an important advancement to powered flight which contributed to the extensive adaptive radiation witnessed in modern birds.

\section{Methods}

Forces of rotation and elevation. Under deep anaesthesia (ketamine $60 \mathrm{mg}$ per kg, xylazine $6 \mathrm{mg}$ per kg, with supplemental ketamine given as needed), we bisected the latissimus dorsi and rhomboideus muscles to expose the brachial plexus and isolate the nerve to the SC. A trachea tube was inserted to provide unidirectional ventilation $\left(80 \% \mathrm{O}_{2}, 20 \% \mathrm{~N}_{2}\right)$ after opening the posterior air sacs. All other components of the brachial plexus were severed to prevent stimulation of adjacent muscles, and the nerve to the SC was mounted on silver bipolar electrodes. We stabilized the bird by clamping the sternal keel, proximal coracoid and vertebral margin of the scapula to a heavy frame and body temperature was maintained at $39^{\circ} \mathrm{C}$ with warmed avian ringers and a heat lamp. A silver wire $(0.38 \mathrm{~mm}$ diameter $)$ was threaded through a small hole drilled in the deltopectoral crest and attached to a Grass T4 force transducer. The humerus was stabilized by inserting a needle ( 23 gauge) into its distal shaft, thus allowing 'free' rotation about the long axis of the humerus while restricting elevation. At wing positions corresponding to the downstroke-upstroke transition and mid-upstroke, a supramaximal stimulus $(0.2-\mathrm{ms}$ pulse, $60 \mathrm{~Hz}$, 500-ms train) was delivered to the nerve of the SC. Substantial torque was produced by the SC around the longitudinal axis of the humerus in both positions. After removing the needle from the shaft of the humerus, we measured forces of humeral elevation by securing a piece of 5-0 surgical silk (compliance, $0.45 \mu \mathrm{m} \mathrm{N}^{-1} \mathrm{~cm}^{-1}$ ) to the humerus at midshaft. This configuration detected the elevational component of force but allowed the humerus to rotate on its long axis. Forces of elevation were consistently lower than forces of rotation.

Excursion of the humerus. We measured the total in situ rotational excursions of the humerus during tetanus of the SC for two starlings. We measured humeral rotation by placing a 23 -gauge pin guided by a rack and pinion through a small hole drilled in the distal head of the humerus. This pin served as a pivot for rotation while restricting the elevational component of movement. We placed a 26-gauge pin perpendicular to the long axis of the humerus, which served as a dial with which to measure the degree of rotation. We removed the 23-gauge pin and allowed the humerus to move during stimulation to measure humeral elevation. We stimulated the nerve tetanically $(60 \mathrm{~Hz} ; 500-\mathrm{ms}$ train duration) and measured humeral rotation with a protractor.

Active and passive length-force. We measured the muscle's passive and active properties at a series of lengths (Fig. 3, top; abscissa) within the muscle's normal in vivo excursion. We established the active length-force curves from maximal twitch responses (single stimulus, $0.2-\mathrm{ms}$ pulse) and measured maximum whole-muscle tetanic force $(60 \mathrm{~Hz}, 500$-ms train) at the end of each experiment at the length coincident with maximum twitch force. After isolating the nerve to the SC (as already described), we deflected the deltoid and propatagialis muscles from the dorsal aspect of the humerus, cut the bone around the tendon's site of attachment, and removed the bone chip together with the tendon. With the bird stabilized to a heavy frame by clamping the sternal keel, proximal coracoid and vertebral margin of the scapula, the bone/ tendon structure was secured to the force transducer with a silk tie (compliance, $0.45 \mu \mathrm{m} \mathrm{N}^{-1} \mathrm{~cm}^{-1}$ ). A force transducer (Grass FT4) was mounted on an adjustable rack and pinion (millimetre calibration), which allowed us to change the muscle's length in millimetre increments. We generated passive lengthforce curves by lengthening the muscle in $1.0-\mathrm{mm}$ increments over its physiological working range. We returned the muscle to the length of 'zero' passive force after each measurement before pulling it to a new length. The active length-force curve was generated by following the same length-change protocol and delivering a single supramaximal stimulus $(0.2 \mathrm{~ms})$ to the nerve at each length. We correlated absolute muscle length to wing angle of elevation and depression (Fig. 3, bottom; abscissa) by manipulating the contralateral wing in the bird after killing (sodium pentobarbital, $100 \mathrm{mg} \mathrm{kg}^{-1}$ ). We dissected the origin of the SC from its attachment on the coracoclavicular membrane and sternum and attached it to a rack and pinion. This configuration allowed us to manipulate wing elevation, depression and rotation, and to correlate these with changes in tendon excursion. We manipulated the humerus in $10^{\circ}$ increments above and below the horizontal.

Received 2 January; accepted 7 April 1997.

1. Brown, R. H. J. Flapping flight. Ibis 93, 333-359 (1951).

2. Dial, K. P., Goslow, G. E. Jr \& Jenkins, F. A. Jr The functional anatomy of the shoulder in the European starling (Sturnus vulgaris). J. Morphol. 207, 327-344 (1991).

3. Simpson, S. F. The flight mechanism of the pigeon Columba livia during take-off. J. Zool. 200, 435443 (1983).

4. Dial, K. P., Kaplan, S. R., Goslow, G. E. Jr \& Jenkins, F. A. Jr A functional analysis of the primary upstroke and downstroke muscles in the domestic pigeon (Columba livia) during flight. J. Exp. Biol. $134,1-16$ (1988).

5. Norberg, U. M. Vertebrate Flight 1-291 (Springer, Berlin, 1989).

6. Rayner, J. M. V. The evolution of vertebrate flight. Biol. J. Linn. Soc. 34, 269-287 (1988).

7. Spedding, G. R., Rayner, J. M. V. \& Pennycuick, C. J. Momentum and energy in the wake of a pigeon (Columba livia) in slow flight. J. Exp. Biol. 111, 81-102 (1984).

8. Ostrom, J. H. Archaeopteryx and the origin of birds. Biol. J. Linn. Soc. 8, 91-182 (1976).

9. Ostrom, J. H. Some hypothetical anatomical stages in the evolution of avian flight. Smithson. Contr. Paleobiol. 27, 1-21 (1976).

10. Sanz, J. L. et al. An Early Cretaceous bird from Spain and its implications for the evolution of avian flight. Nature 382, 442-445 (1996).

11. Hou, L., Zhou, Z., Martin, L. D. \& Feduccia, A. A beaked bird from the Jurassic of China. Nature 377, 616-618 (1995).

12. Chiappe, L. M. \& Calvo, J. O. Neuquenornis volans, a new Late Cretaceous bird (Enantiornithes: Avisuridae) from Patagonia, Argentina. J. Vert. Paleo. 14, 230-246 (1994).

13. Hou, L. A late mesozoic bird from inner Mongolia. Vert. Pal Asiatica 32, 258-266 (1994).

14. Sereno, P. C. \& Rao, C. Early evolution of avian flight and perching: New evidence from the Lower Cretaceous of China. Science 255, 845-848 (1992).

15. Zhou, Z., Jin, F. \& Zhang, J. Preliminary report on a Mesozoic bird from Liaoning, China. Chinese Sci. Bull. 37 (16), 1365-1368 (1992).

16. Olson, S. L. \& Feduccia, A. Flight capability and the pectoral girdle of Archaeopteryx. Nature 278, 247248 (1979).

17. Rayner, J. M. V. in Biomechanics in Evolution (eds Rayner, J. M. V. \& Wootton, R. J.) 183-212 (Cambridge Univ. Press, 1991).

18. Rayner, J. M. V. Form and function in avian flight. Curr. Ornithol. 5, 1-77 (1988).

19. Meyers, R. A. Gliding flight in the American kestrel (Falco sparverius): An electromyographic study. J. Morphol. 215, 213-224 (1993).

20. Tobalske, B. W. \& Dial, K. P. Neuromuscular control and kinematics of intermittent flight in budgerigars (Melopstittacus undulatus). J. Exp. Biol. 187, 1-18 (1994).

21. Spector, S. A., Gardiner, P. F., Zernicke, R. Z., Roy, R. R. \& Edgerton, V. R. Muscle architecture and force-velocity characteristics of cat soleus and medial gastrocnemius: Implications for motor control. J. Neurophysiol. 44, 951-960 (1980).

22. Cohen, A. H., Rossignol, S. \& Grillner, S. Neural Control of Rhythmic Movements in Vertebrates 1-500 (Wiley, New York, 1988).

23. Jenkins, F. A. Jr The evolution of the avian shoulder joint. Am. J. Sci. 293A, 253-367 (1993).

24. Sy, M. Funktionell-anatamische Untersuchungen am Vogelflügel. J. Ornithol. 84, 253-267 (1936).

25. Hazelhurst, G. A. \& Rayner, J. M. V. An unusual flight mechanism in the pterosauria. Paleontology 35 , 927-941 (1992).

26. Wellnhofer, P. in Archaeopteryx 1-30 Ein neues Exemples von Archaeopteryr (Freunde des JuraMuseums Eichstätt, 1988)

27. Wellnhofer, P. in Archaeopteryx 1-47 Das siebte Exemplar von Archaeosteryx aus den Solnhofener Schichten. (Freunde des Jure-Museums Eichstätt, 1993).

28. Sanz, J. L., Chiappe, L. M. \& Buscalioni, A. D. The osteology of Concornis lacustris (Aves: Enantiornithes) from the lower Cretaceous of Spain and a reexamination of its phylogenetic relationships. Novitates 3133, 1-23 (1995).

29. Kurochkin, E. N. A true carinate bird from Lower Cretaceous deposits in Mongolia and other evidence of Early Cretaceous birds in Asia. Cretaceous Res. 6, 271-278 (1985).

30. Sanz, J. L. \& Bonaparte, J. F. A new order of birds (class Aves) from the Lower Cretaceous (Spain). Nat. Hist. Mus. L.A. County Sci. Ser. 36, 39-49 (1992).

Acknowledgements. We thank L. Chiappe, K. Earls, J. Gray-Chickering, C. Kovacs, F. A. Jenkins Jr, D. Ritter, J. Ostrom and T. A. McMahon for critically reviewing the manuscript and for their encouragement; M. Morimoto and A. Valore for technical assistance; and L. L. Meszoely and K. Brown-Wing for Figs 1 and 3, and Fig. 2, respectively. This work was supported by a grant from the NSF.

Correspondence and requests for materials should be addressed to S.O.P. (e-mail: samuel_poore@brown. edu). 